\title{
Incongruity-resolution cases in jokes
}

\begin{abstract}
The incongruity-resolution model is one of the most popular theories that propose an explanation for the strategies underlying humorous texts. In this paper, a taxonomy of incongruity-resolution Cases is proposed according to a relevance-theoretic stance. Then, the extent to which these Cases are exhaustive enough to cover the whole range of possible incongruity-resolution patterns is checked with a corpus of jokes. Furthermore, an analysis is carried out concerning the implications of matching certain kinds of jokes with specific Cases of the taxonomy. Some conclusions on their pragmatic quality and their overall humorous effects are also drawn

Keywords: incongruity; resolution; jokes; humor; relevance theory; frame.
\end{abstract}

\section{Introduction}

Incongruity-resolution (henceforth IR) theory claims that most jokes follow a similar pattern: the hearer processes the text of the joke and suddenly an incongruity is encountered. The hearer then has to find a resolution so as to obtain the intended humorous effects. Since IR predicts a linear processing of the joke until some form of cognitive dissonance turns up (Author, 1997), it fits the relevancetheoretic model of comprehension (Sperber and Wilson, 1995), according to which hearers engage in a mutual parallel adjustment during the interpretation of every chunk of text making up the utterance, centered upon (a) determining the intended explicit interpretation (explicature), (b) deriving possible implicated premises and conclusions (implicatures), and (c) accessing as much contextual information as necessary (contextual assumptions) so as to achieve relevant interpretive outcomes for (a) and (b). Needless to say, this chunk-by-chunk processing is predicted and manipulated by the humorist for the sake of generating humorous effects.

Although several authors have, one way or another, proposed this dual-phase ${ }^{1}$ framework of humorous texts, the research by Suls $(1972,1977,1983)$ is among the most influential proposals, according to which most (if not all) humorous texts follow a fixed pattern:

the perceiver meets with an incongruity (usually in the form of a punch line or a cartoon) and then is motivated to resolve the incongruity either by retrieval of information in the joke or cartoon or from his/her own storehouse of information. According to this account, humor results when the incongruity is resolved; that is, the punch line is seen to make sense at some level with the earlier information in the joke. (Suls, 1983: 43)

This simple schema accounts for most instances of humorous discourse (Ritchie, 2006: 252). Hirt and Genshaft (1982: 453), correctly stress that "the sudden discovery achieved by a reorganization of

1. Typically conceptualized as two phases, but also understood as a three-phase phenomenon. For example, Hull et al. (2016: 3) claim that Suls' is a three stage information processing model, according to which humor involves: "a set up stage where an expectation is created, an incongruity stage where the expectation is violated, and a resolution stage where the discrepancy between the expected and the actual state of affairs is bridged". 
symbols and meanings into a surprising new relationship is the source of gratification in humor... [which] reflects a successful mastery of the environment or resolution of the challenge presented by the humor paradox on incongruity". ${ }^{2}$ However, as will be pointed out in Section 2.3 below, the way this incongruity-resolution is achieved varies according to two broad areas of joke processing. On the one hand, incongruities may arise when constructing an appropriate scenario for the comprehension of the joke (so-called make-sense frame, see below). On the other hand, incongruities may turn up when processing the text of the joke for relevance (involving cognitive strategies such as reference assignment, disambiguation, concept adjustment, etc.). Beyond this broad classification, several Cases will be proposed in Section 3 below. Before, in Section 2 some issues concerning IR will be commented upon. Finally, Sections $4-5$ will be devoted to an analysis of the corpus of jokes collected for this paper and possible conclusions that may be drawn from this analysis.

\section{Some issues concerning IR}

\subsection{Role of expectations}

Suls (1972: 85) states that the information obtained from the processing of the initial part of the text serves as an aid to predict the forthcoming text (Dynel, 2012: 158). But there is little that a hearer can actually expect from subsequent text, apart from a congruence with the situation just constructed in order to make sense of the joke. When Martin (2006: 64) writes about how "joke setup causes the listener to make a prediction about the likely outcome. When the punch line does not conform to the prediction, the listener is surprised and looks for a cognitive rule that will make the punch line follow from the material in the joke setup", he is mainly focusing on the initial construction of a situation (frame, schema, etc.) in order to make sense of the joke. No doubt, this mental construction allows for expectations which are eventually disconfirmed (Fearman, 2014: 4). However, concerning the forthcoming text of a subsequent part of the joke, only on very few occasions can the hearer anticipate which text may be coming up. Suls proposes examples such as (1):

\footnotetext{
2. Although Suls is indeed regarded as the main analyst of the incongruity-resolution model, other authors have previously hinted at this humorous pattern. For example, Keith-Spiegel (1972: 8) underlines the importance of Beattie (1776), for whom "laughter arose when two or more inconsistent or unsuitable circumstances were united into one complex assemblage", and also comments on other authors such as Kant (1790) and Schopenhauer (1819). According to the former, laughter is "an affection arising from the sudden transformation of a strained expectation into nothing". Similarly, Schopenhauer viewed laughter as arising from "the sudden perception of the incongruity between a concept and the real objects which have been thought through in some relation, and the laugh itself [to be] just the expression of this incongruity". Freud (1916) is also worth mentioning in stressing the contrast between frame and situation, including effects of cancellation and/or confirmation of expectations and presumptions, and the resolution. The list of authors who, one way or another, deal with incongruity-resolution is long. In this paper I have centered upon those which fit more nicely a relevance-theoretic stance. For further references on the subject see, among others, Attardo (1994) and Thielemann (2015). The author is grateful to a reviewer for pointing the latter out to me.
} 
(1) One prostitute said to another, "Can you lend me ten dollars until I get back on my back?".

This is probably one of the few examples in which the hearer is indeed entitled to expect a specific chunk of text, given the fixed structure of the idiom "get back on one's feet". In this joke, these expectations are contradicted, hence generating an incongruity. On normal occasions, though, hearers can only build up expectations of congruence with the situation previously constructed or with interpretations already selected for that initial part of the joke. In other words, the subsequent part of the joke is indeed incongruous, but not with some expected text, but with previously inferred situations and interpretations taken on board so far during the comprehension of the joke.

\subsection{Incongruity, resolution, or both}

In this paper, it will be assumed that incongruities must be resolved before any humorous effects may be produced. Incongruities are not generally welcome, and only by finding a resolution that reconciles the incongruous parts, can the hearer obtain the expected outcome. Indeed, ruling out incongruities is a natural, biologically rooted mechanism of human cognition, and "any organism interested in improving its cognitive environment will attempt to minimise inconsistencies in its representation system... A hearer aiming at an interpretation consistent with the principle of relevance must find an interpretation that either eliminates or prevents the inconsistencies that the incongruous propositional contents might give rise to" (Curcó, 1998: 311-312).

However, several authors have proposed other possibilities regarding incongruity and/or resolution. For example, incongruity alone may be sufficient to trigger a humorous effect, as stated by Nerhardt (1976) in the weight-judging paradigm, according to which the clash of mental representation suffices to generate humor.

Of course, resolution is not always easy or straightforward. In cases of nonsense humor, for example, the speaker does not expect a resolution of incongruities but a generation of confusion. Besides, in many jokes and punning configurations (especially those used in advertising), the hearer is not expected to solve the incongruity, but to entertain clashing interpretations humorously without discarding one of them. Consider the joke in (2) and the advertisement in (3):

(2) A young husband with an inferiority complex insisted he was just a little pebble on a vast beach. The marriage counselor, trying to be creative, told him, "If you wish to save your marriage, you'd better be a little bolder".

(3) Product advertised: Savings account.

Image: A policeman climbing up a ladder and trying to grab a wad of bank notes lying on the cornice of a building.

Text: There is another way of saving money. 
Joke (2) plays with the homophony of bolder and boulder. In the context of counseling, the first interpretation should be selected as the intended one, but in the joke the character talks metaphorically about feeling like a pebble (which is retained in the hearer's short-term memory store), thus making the "boulder interpretation" eventually as likely as the other, and both end up being entertained simultaneously. Similarly, in (3) the most likely interpretation of saving money is "putting money aside in the bank", because of the lexical frequency of the joint appearance of these words. But in this advertisement, the picture depicted in the advertisement (the policeman trying to get the wad of bank notes) makes another interpretation of save money, namely "to rescue money", equally accessible. This simultaneity of interpretations leads to an inferential puzzlement in the audience, and hence to more attention being paid to the ad, as intended by its designers.

\subsection{Frame apprehension vs. discourse inference}

There are two broad areas of joke processing that may be exploited for incongruity-resolution. The first one exploits the mental construction of a situation in order to make sense of the joke. The second is centered upon the inferential strategies performed in order to turn the schematic literal meaning of the text of the joke into fully contextualized interpretations. In other words, certain jokes base the incongruity on the hearer's construction of an appropriate mental situation (frame, schema, script...) to make sense of what is happening in the story depicted within the joke, which turns out to be eventually incorrect. Others, by contrast, play with conflicts that hearers encounter when they are processing the verbal content of the joke (with inferential operations such as reference assignment, disambiguation, etc.). The former will be called frame-based jokes, while the latter will be labeled discourse-centered jokes.

In previous research, the term make-sense frame was proposed in order to account for the first source of incongruity: the construction of an appropriate situation to make sense of the joke (see Author, 2013a, 2013b, 2016). The term refers to the extraction of general information about the world and everyday situations that is stored as accessible chunks of encyclopedic information (specifically stored as "I conceptualize $\mathrm{X}$ as $p$ " or as a more factual "I believe that $p$ "). This information is often retrieved unconsciously in order to make sense of the intended scenario for the comprehension of the joke. The term covers other labels typically used for this kind of information retrieval, such as frame, schema or script, which often exhibit a great deal of overlapping in their scopes (Author, 2016: 84-85). Tannen (1993: 16) calls them structures of expectations, since "on the basis of one's experience of the world in a given culture (or combination of cultures), one organises knowledge about the world and uses this knowledge to predict interpretations and relationships regarding new information, events, and experiences".

Concerning discourse-centered jokes, in this paper the relevance-theoretic picture of 
comprehension is followed (Sperber and Wilson, 1995). According to this theory, comprehension entails a little bit of decoding and a large amount of inference in order to turn the schematic meaning of the words uttered into fully contextualized propositions. As was mentioned above in passing, comprehension is a chunk-by-chunk mutual parallel adjustment of the inferential enrichment and contextualization of words intended to obtain explicit interpretations (explicatures), the derivation of implicated premises and conclusions (implicatures), and accessing contextual information (a set of assumptions). The process of comprehension starts with the identification (i.e. decoding) of the basic semantic representation of the utterance (logical form), which is then enriched at the explicit level with inferential operations such as:

(a) Reference assignment, typical of indexicals (i.e. pronouns and adverbs) and proper names that are empty and have to be filled with a referent in a specific conversational context, as in (4a), enriched into (4b).

(b) Disambiguation. Sometimes the hearer has to choose between two senses of the same word as possibly matching the one intended by the speaker, as in (5).

(c) Saturation. It takes place when the utterance demands from the hearer a kind of "inferential gap-filling" of some elided part of the utterance without which the utterance makes little sense. Typical examples include the part in square brackets listed in (6).

(d) Concept adjustment. On many occasions (if not all), the concept coded by a word is adjusted pragmatically, in such a way that the prototypical concept associated with that coded word is slightly different and merely resembles the one actually communicated in a context (called ad hoc concept). This communicated concept may be narrower than the coded concept, as in (7), or broader, as in (8). In all of these cases, the ad hoc concept that is eventually communicated (DRINK* and EMPTY*) only resembles the concept literally coded in the utterance (see Carston, 2002, among others).

(4) a. She was there with her and Thomas.

b. [Mary was at the party with Helen and Thomas Smith].

(5) I saw John by the bank [river bank/financial institution].

(6) Paracetamol is better [than what?] [for what?].

Louise is a better candidate [than whom?] [for what?].

(7) I am worried about Jim... He drinks too much.

[specifically, Jim drinks too much alcohol].

(8) We entered the pub but we left since it was empty.

[not literally empty; rather, with few people, including the waiter].

The outcome of these inferential strategies is the so-called proposition expressed by the utterance which, when communicated, is called explicature. Often the explicature matches the speaker's intended interpretation, but on other occasions the speaker intends some implicated interpretation as 
well (implicature), and hence the explicature becomes part of the "information plus context" that the hearer needs to reach that implicated interpretation.

Implicatures may be arranged on a continuum between strong and weak. Consider this example (adapted from Carston, 2009):

(9) Tom: How was the party? Did it go well?

Ann: There wasn't enough drink and everyone left early.

(10) a. There wasn't enough alcoholic drink to satisfy the people at the party and so everyone who came to the party left it early, roughly before 2 o'clock.

b. The party did not go well at all.

c. Parties in which alcohol is scarce and people leave early are not good.

d. Ann thinks alcohol is essential in parties.

e. Ann only enjoys herself at parties when she is surrounded by many people.

When Tom interprets Ann's utterance, he decodes her words and enriches them at the explicit level: the concept drink is adjusted (narrowed) into specifically alcoholic drink, the scope of everyone is narrowed to "everyone at the party", and early has to be interpreted as the time in their culture in which leaving a party at a certain time is considered early (for instance, 2 o'clock). The resulting proposition would be the explicature in (10a). Of course, as an answer to Tom's question, she also strongly implicates (10b) (an implicated conclusion), in the sense that it is clear that she backs up the derivation of this implicature. This is obtained by pairing the explicature in (10a) with encyclopedic information about what it takes for parties to be successful (the implicated premise in 10c). However, Tom may also derive further implicatures, this time weaker (Ann probably did not intend to communicate them, but these are anyhow triggered by her utterance), such as (10d) or even weaker ones such as $(10 \mathrm{e})$, this time derived by his sole responsibility. Very often, in the case of humor the hearer may derive weak implicatures beyond those ostensively intended by the speaker as part of the desired humorous effects.

Relevance theory is particularly suited to account for incongruity-resolution in jokes. It describes the inferential activity of an evolved psychological ability that invariably selects the most relevant interpretation by making comparative judgments among competing interpretations and opting for the one that provides the highest relevance. In general, hearers invariably opt for the most relevant interpretation that fits the conditions of "effects vs. effort". This is actually crucial for the incongruityresolution pattern, since it involves playing with the accessibility of frames or interpretations for certain stretches of the joke (bound to be selected due to their relevance), which are invalidated at some stage.

Finally, it should be noted that very often the construction of frames and the inference of interpretations from joke discourse are combined in the generation of humorous effects, especially 
when the source of incongruity is discourse-centered. Consider the joke in (11) (Author, 2016: 39):

(11) A policeman in Washington D.C. stops a lady and asks for her license. He says "Lady, it says here that you should be wearing glasses". The woman answers "Well, I have contacts". The policeman replies "I don't care who you know! You're getting a ticket!"

In this example, the speaker can predict that the hearer will build up a mental scenario of the joke (make-sense frame). In the cumulative interpretive process, the word glasses will be retained in the short-term memory store and will aid the hearer (and save mental effort) in disambiguating the subsequent word contacts into "contact lenses". This "contact lenses sense" is highly relevant and accessible and the hearer will not even be aware that any other sense of contacts was possible. When the policeman says "I don't care who you know!', an incongruity arises with the assumptions brought to bear so far in the interpretation of the joke, since the other sense of contacts (influential people she knows) had not even been noticed. The speaker then forces the hearer to backtrack and select this second sense despite its being less relevant in the initial context of the joke.

\subsection{Why is incongruity humorous?}

Incongruities are annoying, they demand additional processing effort and, nevertheless, in jokes they end up being entertained positively and humorously. Several reasons have been put forward to account for this paradox. In previous research (Author, 2003, 2016), several explanations are provided for this pleasurable outcome of incongruity, among others:

(a) Expectations of humorous effects as part of the information shared between the interlocutors (if the interlocutors share the information about being currently under a non-serious kind of conversation, they can accept alterations of normal communicative norms, the introduction of incongruities for the sake of humor, etc.).

(b) Pleasure in solving incongruities (when we "get" a joke, we feel a sense of discovery rather like the sense of triumph when we solve a problem).

(c) Realization of having been fooled by the speaker (the hearer is both surprised and also fully aware of having been fooled by the speaker, a realization that the hearer is supposed to accept with amusement, with the feeling of having been taken in, but not necessarily in an unpleasant way).

(d) A positive interaction of the joke with the addressee (the hearer's personal beliefs, etc., together with information accessible to the hearer during the conversation, influence the joker's achievement of the humorous intention).

One further element that plays a part in the eventual enjoyment of incongruity is the degree of discrepancy between the expected interpretation (or accessible information) and the "forced" interpretation (or new information) after resolution. For schema incongruity theory, moderate 
discrepancies can be successfully resolved, leading to more positive subsequent responses through a psychological reward mechanism (Halkias and Kokkinaki, 2016). In this sense, there is no agreement on whether or not very difficult resolutions of incongruity reduce likelihood of a humorous outcome (Fearman, 2014: 11-14). For example, Plester (2016: 18) states that surprise, unexpectedness and incompatibility are experienced as funny and the bigger the discrepancy the funnier the joke (also supported by Yoon, 2013: 361, among others). By contrast, for Hirt and Genshaft (1982: 454), humor increases directly with ease of information processing, and hence very complex and incongruous humor should be too difficult to integrate and find closure for.

\section{A new taxonomy of IR Cases}

In this paper a new taxonomy of twelve IR Cases is proposed and its applicability checked upon a corpus of five hundred jokes. This taxonomy results from the combination of a number of parameters:

Firstly, as suggested above, a differentiation is made between discourse-centered incongruity and frame-based incongruity. The former is related to the inferential strategies that the hearer applies to the coded input (the joke) so as to turn it into a fully contextualized proposition (reference assignment, disambiguation, concept adjustment, saturation), whereas the latter is focused on the situation that the hearer constructs to make sense of what is happening in the joke (what was called make-sense frame above).

Secondly, a three-fold classification of resolutions is proposed depending on what the hearer is expected to do in order to solve the incongruity:

a. Discourse-centered resolution, when the hearer has to perform a supplementary inferential operation to make sense of the incongruity found in some portion of the text of the joke, for instance to select a previously undetected sense of a word, to locate a different referent for an indexical from the one initially chosen, to opt for a different ad hoc concept for a word in a context, etc.). This applies only to inferential strategies intended to obtain an explicit interpretation of the joke (explicature).

b. Frame-based resolution, when the hearer has to alter the current make-sense frame constructed for the joke and replace it with a different frame that reconciles the incongruity.

c. Implication-based resolution, which applies to cases in which the hearer derives a number of implicatures beyond the comprehension of the text of the joke in order to resolve the incongruity and derive the intended humorous effects. These implicatures are not directly tied to the explicit interpretation of the joke (explicature) but depend on the hearer's ability to access specific contextual information that allows for their derivation when the hearer faces both discourse-centered and framebased incongruities.

Finally, a distinction should be made between incongruities whose source is located in the setup of the joke and those whose source is situated in the punchline. The former often demand some kind of inferential backtracking from the hearer, that is, to return to an already processed part of the joke 
and re-interpret it in the light of the new evidence arising from the processing of a subsequent stretch of the text. On the other hand, the latter demands the hearer's participation with new interpretations for the whole joke (or at least for its last part) or the derivation of implicatures that are necessary to make sense of the joke and obtain the desired effects.

Crucially, the source of the incongruity and the actual identification of the incongruity are often located in different parts of the joke. What interests us in this taxonomy is the element or situation that allows for the incongruity and where it is located, not the location of its resolution or its identification by the hearer. Take, for instance, the following example (Author, 2016: 102):

(12) Tom and Jim talking to each other, Tom says: "You know, Jim, my wife and I were very happy for 25 years". His friend asks, "And then... what happened?" "We met", replies Tom.

In this joke, the hearer initially activates a typical scenario of the happily married couple, but the punchline of the joke invalidates this frame and forces a resolution involving a replacement with a different frame, that of unsatisfactory marriage. However, the source of the incongruity is not located in the punchline, but in the setup, specifically in the underdetermined phrase very happy for 25 years, which contains unarticulated constituents. In the initially activated make-sense frame, the phrase is inevitably understood as "very happy [together] for 25 years", but is later reinterpreted as "very happy for 25 years [before meeting]". Therefore, the joke would exhibit a discourse-centered incongruity, whose source of incongruity is located in the setup, and the joke forces the construction of an alternative scenario for the joke (frame-based resolution).

The combination of these three parameters yields the twelve Cases that are listed in Table 1.

\begin{tabular}{||c|c|c|c||}
\hline & Type of incongruity & Location & Type of resolution \\
\hline 1 & frame-based & setup & discourse-centered \\
\hline 2 & frame-based & punchline & discourse-centered \\
\hline 3 & frame-based & setup & frame-based \\
\hline 4 & frame-based & punchline & frame-based \\
\hline 5 & frame-based & setup & implication-based \\
\hline 6 & frame-based & punchline & implication-based \\
\hline 7 & discourse-centered & setup & discourse-centered \\
\hline 8 & discourse-centered & punchline & discourse-centered \\
\hline 9 & discourse-centered & setup & frame-based \\
\hline
\end{tabular}




\begin{tabular}{||c|c|c|c||}
\hline 10 & discourse-centered & punchline & frame-based \\
\hline 11 & discourse-centered & setup & implication-based \\
\hline 12 & discourse-centered & punchline & implication-based \\
\hline
\end{tabular}

Table 1. Proposal of incongruity-resolution Cases.

\subsection{Make-sense frame-based incongruities}

Case 1: [frame-based incongruity] [setup] [discourse-centered resolution]

In theory, in this Case the hearer constructs a make-sense frame in the setup of the joke that ends up becoming incongruous with the frame built up for the subsequent part of the joke. The hearer then reconciles the incongruous parts by resorting to some discourse-centered inferential strategy (reference assignment, disambiguation, etc.). It is evident that finding joke samples for this type Case is bound to be difficult and, in fact, no samples were found in the corpus collected for this paper. Indeed, when addressees find a frame-based incongruity, they normally resort to building up another frame that replaces the initial one and provides coherence for the whole joke. It is comprehensible that out of a combination of elements we may end up with Cases such as 1 (and 2 below) which are not only infrequent, but probably inexistent in samples of jokes such as the ones analyzed in this paper.

Case 2: [frame-based incongruity] [punchline] [discourse-centered resolution]

In this Case, a make-sense frame is built up unobstructed until, in the final part of the joke (punchline), the frame no longer applies, so there is an incongruity with the assumptions that she has taken on board so far in the interpretation of the joke. The resolution of the incongruity demands from the hearer a re-interpretation of some part of the joke. No samples of this Case were found in the corpus. In previous research, jokes such as (13) were proposed (Author, 2016: 104):

(13) A man calls his family doctor. Man: "Doctor, for the last week my wife has thought that she was a rabbit". Doctor: "OK, bring her in and I'll try to help". Man: "Fine, but whatever you do, don't cure her".

In (13), the hearer activates the typical frame of "visit to the doctor". When the hearer encounters the word rabbit, little mental effort is devoted to finding the exact quality of the wife's resemblance to a rabbit. At the end of the joke, though, the phrase Don't cure hercontradicts the typical frame for being at the doctor's, which typically includes a desire to get cured. The hearer then is forced to backtrack and make a conceptual adjustment of the word rabbit and find out some quality typically associated with rabbits which can possibly be applied to a human being in such a way that no cure is desired. 
Case 3: [frame-based incongruity] [setup] [frame-based resolution]

In this Case, the hearer finds an incongruity during the construction of an appropriate make-sense frame for the joke. The source of this incongruity is located in the setup of the joke, and the resolution demands some frame alteration or substitution so as to obtain a congruent interpretation for the whole joke. Examples from the corpus include the following:

(14) A man had just been laid off from work. He was standing on the railing of a high bridge getting ready to jump off, when he happened to look down and see a little man with no arms dancing all around on the river bank below. He thought to himself, "Life isn't so bad after all", and got off the railing. He then walked down to the river bank to thank the little man for saving his life. "Thank you", he said. "I was going to jump off that bridge and kill myself, but when I saw you dancing even though you have no arms, I changed my mind". "I am not dancing", the armless man replied bitterly. "My asshole itches, and I can't scratch it".

In (14), the make-sense frame for the dancing of the little man in the setup has an initial accessible construction, but it turns out to be erroneous and has to be replaced (after the character's own explanation) upon reaching the end of the joke.

Case 4: [frame-based incongruity] [punchline] [frame-based resolution]

The structure of this Case exhibits an incongruity based on a choice of a make-sense frame that is eventually invalidated. The source of the incongruity is located in the punchline of the joke and its resolution requires a change in the initially selected frame for the whole joke. The main difference between this Case and the previous one is that, in Case 3, the setup has multiple possible interpretations in terms of make-sense frame construction (one of them likely but eventually incorrect), whereas in this Case the hearer constructs a frame for the whole joke unobstructed until the hearer is suddenly forced to replace the frame with a different one, typically for the whole joke. Examples from the corpus would be (15-17) below on the topic of "marriage". In (15), the initial frame of spouses working on a marriage "together" is finally invalidated and replaced with a different scenario. In (16), marriage is supposed to be a time of happiness, but this frame is invalidated at the end of the joke. Finally, in (17) the end of the joke invalidates the initial frame of divorce as a painful time for the spouses involved:

(15) Some people ask the secret of Anthony's long marriage. They take time to go to a restaurant two times a week: a little candlelight dinner, soft music, and a slow walk home. The Mrs. goes Tuesdays; He goes Fridays.

(16) Returning from her vacation, the young secretary was telling anyone who would listen about 
what a fun time she had. She then asked for two weeks leave in which to get married. "But you just had two weeks off", said the boss. "Why didn't you get married then?" "What... and ruin my vacation?" she whined.

(17) I have this friend who has a real dilemma. His wife won't give him a divorce until she figures out a way of doing it without making him a happy man.

Case 5: [frame-based incongruity] [setup] [implication-based resolution]

This Case is not very frequent. Its structure predicts an incongruity resulting from the construction of an adequate make-sense frame for the setup of the joke. The hearer's attempt to solve it is mainly carried out through the derivation of implicatures beyond the inferred explicit interpretation of the joke. Probably, the reason for the infrequent samples is due to the fact that normally hearers resort to an alternative frame when solving incongruities, rather than derive implications from an existing (and eventually incorrect) one. An example of this Case is (18):

(18) A man was traveling down a country road when he saw a large group of people outside a house. He stopped and asked a person why the large crowd was there. A farmer replied, "Joe's mule kicked his mother-in-law and she died". "Well", replied the man, "she must have had a lot of friends". "Nope", said the farmer, "we all just want to buy his mule".

Here, the setup of the joke is invariably understood as "friends and relatives gathered together at a funeral". However, there is another highly unlikely interpretation of the situation depicted. Although the main way to resolve the incongruity is by deriving implicated premises and conclusions about the stereotypical character mentioned (mother-in-law), often negatively connoted in jokes, the hearer also has to replace the initial frame with a new one fitting the whole joke.

Case 6: [frame-based incongruity] [punchline] [implication-based resolution]

By contrast, this Case is rather frequent. The hearer encounters an incongruity related to the construction of a suitable make-sense frame for the joke. This time, the source of the incongruity is located in the punchline, and the resolution of this incongruity demands the derivation of a number implications. Consider this joke (Author, 2016: 107-108):

(19) A woman in bed with a man. The phone rings and she takes the call. "Yes darling... No problem... OK... I'll see you later". The man asks: "Who was that?" "It was my husband. He's going to come home very late tonight because he is in an important meeting with you".

(20) a. The man and the woman are lovers.

b. The woman's husband has a lover.

c. She knows that her husband has a lover. 
d. Her lover and her husband know each other.

e. Her husband does not know that this man is his wife's lover.

This joke leads the hearer to alter the initially constructed frame for the situation depicted in the joke, and the eventual humorous effects lie in a number of stronger or weaker implications such as (20a-e), which the hearer has to take full responsibility in constructing after the punchline alters the accessible frame construction. This joke fits Jodłowiec's (2008: 79) comment that in some jokes "the punchline leads the audience to suddenly access a whole array of weakly communicated assumptions, which are formed on the basis of background information that the joke-recipient has immediate access to via concepts that have been made available to him or her by processing the setting".

This Case in the taxonomy also fits some of Curcó's (1997) analyses of humor. Basically, she proposes that a hearer often finds that he/she has taken on board an assumption that either does not hold, or whose value the speaker tacitly questions, for instance, by implicitly expressing a dissociative attitude to it. For Curcó, it is enough to look at the subset of the hearer's beliefs that are retrieved from memory or constructed on the fly in interpreting an utterance, and to consider their relative saliency at any given time. Her analysis shows how the speaker leads the hearer to entertain two contradictory propositional contents: one is a strongly implicated premise (which Curcó labels key assumption). This premise clashes with an accessible (though so far unaccessed) assumption in the context of interpretation (which Curcó labels target assumption). She suggests examples such as (21):

(21) There is something tragic about the enormous number of young men there are in England at the present moment who start life with a perfect profile and end up by adopting some useful profession (Oscar Wilde).

Target assumption: A useful profession is a cause for congratulation (from the hearer's encyclopedic knowledge).

Key assumption: A useful profession is a cause for commiseration [strongly implicated from (21)].

\subsection{Discourse-centered incongruities}

\section{Case 7: [discourse-based incongruity] [setup] [discourse-based resolution]}

This is a typical joke structure. The hearer engages in a pragmatic enrichment of the text of the joke in order to reach an interpretation. The speaker predicts that one interpretation of an element located in the setup is bound to be selected because it is more accessible (i.e. likely to turn out more relevant), and that the hearer will not even notice the existence of other possible interpretations. Upon reaching the punchline, the hearer realizes that another interpretation of that initial chunk of text was possible, but remained undetected until the speaker foregrounded it. This new stretch of text forces the hearer 
to engage in some inferential backtracking and re-interpretation of that initial part of the joke in a different way, so that the joke finally achieves congruence as a whole. This pattern fits Dynel's (2012: 159) garden-path mechanism, according to which "the first part of the text must entail covert ambiguity, with only one meaning being effortlessly accessible on first reading/hearing, and the second part of the text must invalidate the earlier inference and prompt the interpreter to backtrack and reprocess the initial part of the text in order to appreciate the ambiguity and the alternative hitherto unobserved meaning", and also other joke schemas proposed such as Author's (2003) "multiple graded versus single covert interpretation schema" and Ritchie's (2004) "forced reinterpretation model". The Case itself applies to all the inferential sub-stages devoted to building up the explicature of the joke. Consider these examples:

(22) Nurse: Doctor, there is a man in the waiting room with a glass eye named Brown.

Doctor: What does he call his other eye?

a. [a man] [in the waiting room] [with a glass eye] [named Brown].

b. [a man] [in the waiting room] [with a glass eye named Brown].

(23) Two small boys, not yet old enough to be in school, were overheard talking at the zoo one day. "My name is Billy. What's yours?" asked the first boy. "Tommy", replied the second. "My Daddy's an accountant. What does your Daddy do for a living?" asked Billy. Tommy replied, "My Daddy's a lawyer". "Honest?" asked Billy. "No, just the regular kind", replied Tommy.

(24) The village blacksmith finally found an apprentice willing to work hard at low pay for long hours. The blacksmith immediately began his instructions to the lad, "When I take the shoe out of the fire, I'll lay it on the anvil; and when I nod my head, you hit it with this hammer". The apprentice did just as he told. Now he's the village blacksmith.

(25) A woman meant to call a record store but dialed the wrong number and got a private home instead. "Do you have 'Eyes of Blue' and 'A Love Supreme'?" she asked. "Well, no”, answered the puzzled homeowner. "But I have a wife and eleven children". "Is that a record?" she inquired. "I don't think so", replied the man, "but it's as close as I want to get".

(26) Patient (to cosmetic surgeon): Will it hurt me, doctor?

Surgeon: Only when you get my bill, Mrs Brown.

Joke (22) plays with the initial identification of two possible arrangements of words and their syntactic organization (semantic representation or logical form), one of them likely but eventually incorrect (22a), and another more unlikely but eventually correct, as the hearer discovers in the punchline of the joke (22b). (23) plays with the recovery of the unarticulated constituents in the sub-sentential utterance Honest?, namely "Are you honest?" (more likely but eventually incorrect) and "Is your father honest?" (unlikely but eventually correct). (24) plays with two possible referents for the indexical it in "Hit it with this hammer". Again, one is likely (the shoe) but the eventually correct one turns out to be 
different (the blacksmith's head). In (25), the speaker plays with the disambiguation of two possible senses of record. Finally, in (26) the hearer is expected to adjust the concept hurt so as to meet the expectations of relevance, initially as a physical quality and then with a more abstract connotation.

Case 8: [discourse-based incongruity] [punchline] [discourse-based resolution]

This Case is similar to the previous one. This time, the source of the discourse-centered incongruity is located in the punchline of the joke. This is the typical case in which two senses of an ambiguous part of the joke are entertained (and enjoyed) simultaneously, rather than one simply replacing the other, because the joke ends with an ambiguity and similar candidate interpretations, and the resolution of the incongruity comes after the whole joke has been inferred (Author, 2016: 109). An example is (27) below:

(27) Do you know what happens if you don't pay your exorcist?

You get repossessed!

The joke plays with the polysemy of repossessed placed at the end of the joke. Due to the interpretation of the setup, both interpretations of the word are equally likely, thus generating puzzlement in the hearer, who is not expected to rule out one of them, but to entertain both humorously.

Case 9: [discourse-based incongruity] [setup] [frame-based resolution]

This Case is less frequent, since it involves discourse-centered incongruity whose source is located in the setup, and the resolution of this incongruity demands a variation of the make-sense frame that has been constructed so far in the interpretation of the joke. Joke (28) is illustrative:

(28) A young married woman was discussing her sex life with a girlfriend. The girlfriend asked, "Do you talk to your husband when you're making love?" She thought about it a minute then said, "Well, no. But I could. I mean he has a cell phone and all".

Here, the joke plays with the ambiguity of "while you're making love" in the setup of the joke, whose relevant interpretation inevitably involves the inferential retrieval of the unarticulated constituent "with your husband". The resolution of the incongruity does not only depend on a change of unarticulated element (which, being so stereotypically obvious, the hearer may not even be aware of having retrieved it), but mainly on the change of make-sense frame from "sex within marriage" to "sex outside marriage". Besides, as has already been mentioned in passing, the hearer may also derive a number of (weak) implicatures from the joke, even if not overtly intended, for example about the woman never having sex with her husband or only enjoying it with a lover. 
Case 10: [discourse-based incongruity] [punchline] [frame-based resolution]

This Case is also very uncommon, the difference with Case 9 being the location of the source of the incongruity, now placed in the punchline. Very few samples of this pattern were found in the joke corpus. One of them would be (29), in which the hearer is expected to engage in an adjustment of the concept idiots at the end of the joke (the main source of incongruity), and then re-construct the frame in order to fit the new quality of the student after this inferential strategy:

(29) A college physics professor was explaining a particularly complicated concept to his class when a pre-med student interrupted him. "Why do we have to learn this stuff?" the frustrated student blurted out. "To save lives", the professor responded before continuing the lecture. A few minutes later the student spoke up again. "So how does physics save lives?" The professor stared at the student without saying a word. "Physics saves lives", he finally continued, "because it keeps the idiots out of medical school".

Case 11: [discourse-based incongruity] [setup] [implication-based resolution]

In this Case, the source of the incongruity is discourse-centered and located in the setup of the joke. The incongruity is based on inferential strategies performed to turn the coded input into a contextualized proposition. The resolution of the incongruity demands from the hearer the derivation of a number of implications from the text of the joke, as in (30-31):

(30) In olden times, it is reported that sacrifices were made at the altar. Since then, weddings have been held there, and times haven't changed at all!

(31) A man happened to meet his ex-wife at a party, and after a few drinks, he suggested that they might have another try at marriage. His ex-wife sneered in reply, "Over my dead body!" He downed his drink and replied, "Well, I see you haven't changed one little bit".

Both jokes are based on concept adjustment. In (30), the hearer is expected to adjust the concept sacrifice, which is connoted differently in the joke (death-related vs. marriage-related sacrifices). However, the hearer is expected to solve the incongruity mainly by deriving a number of implications about the qualities of marriage. A similar case is (31), in which the concept dead body is adjusted twice and never processed literally, once concerning a metaphorical expression, and once when commenting on the woman's interest in sex. Again, the hearer is expected to use the new (ad hoc) concept as a premise to derive implications on the quality of their marriage and sex life therein.

Case 12: [discourse-based incongruity] [punchline] [implication-based resolution] Finally, in this Case we have a similar structure to the previous pattern, since implicated premises or 
implicated conclusions derived from the joke are the keys to the eventual humorous effects. But this time, the source of the incongruity is located in the punchline of the joke. Consider these jokes:

(32) A man walks into a bar and orders two drinks. As the bartender watches he drinks one drink and pours the other one on his hand. He orders two more drinks and does the same thing. The third time the bartender asks him what's going on. "Why are you pouring that drink on your hand?" The man smiles at him, winks and says "I'm trying to get my date drunk".

(33) A new arrival, about to enter hospital, saw two white coated doctors searching through the flower beds. "Excuse me", he said, "have you lost something?" "No", replied one of the doctors. "We're doing a heart transplant for an income-tax inspector and want to find a suitable stone".

In both jokes, the hearer is expected to engage in an adjustment of the coded concepts date and stone, placed in the punchline of the joke, so as to satisfy the expectations of relevance raised by the joke. In (32), the decoded concept date is broadened to include the man's hand and the sexual activity performed with it. On the other hand, in (33) the hearer broadens the concept stone, some of whose qualities must be applicable metaphorically to the lawyer's heart (and personality). However, in my opinion the resolution of this discourse-centered incongruity entails more than simply adjusting a coded concept into an appropriate (ad hoc) concept, but, rather, in the derivation of a number of implicatures concerning the man's lack of sexuality and the intended criticism on the personality of lawyers. In general, there is no guarantee that the hearer will stick to discourse-centered resolutions, and he/she may further engage in deriving strong implicatures or weaker ones by his/her sole responsibility in his/her search for relevance.

\section{The study}

The main aim of this paper is to check the extent to which these twelve Cases are exhaustive in covering all instances of IR in jokes. For this purpose, a corpus of five hundred jokes were randomly selected from the online joke repository jokes2go (www.jokes2go.net) and then analyzed. The main procedure used was as follows:

First, jokes from the different sections of the repository were collected. It should be noted that some sections at the website contain more jokes than others. The jokes finally collected were randomly taken from the following sections: marriage (88), sex roles (20), bar (55), travel(6), sex (98), blonde (19), jobs (30), doctor (73), religion (6), lawyer (64), sport (14), family (12) and other (several jokes not fitting previous sections) (15). All of the jokes fitted, one way or another, the incongruityresolution schema, although some exhibited difficult ascription to a specific Case. Overall, the main problematic jokes were those based on stereotype-consistent information, such as (34) below: 
(34) Yesterday, scientists in the United States revealed that beer contains small traces of female hormones. To prove their theory, they fed one hundred men twelve pints of beer and observed that $100 \%$ of them started talking nonsense and couldn't drive.

In Author (2002, 2005), a distinction was made between the representations which are considered people's own thoughts (i.e. personalor private beliefs), and those which they regard as belonging to a community (cultural beliefs), which may match, contradict, overlap with, or complement each other. The latter require metarepresentational storage in the form "in this culture/community it is believed that $p$ ", whereas the former are stored directly as factual representations in the form "I believe that $p$ ". This dual form of storage allows people to have personal beliefs on some issues, and still be aware of stereotypes lingering on in society about these very same issues. Therefore, stereotype-consistent jokes should be incongruous for people whose private beliefs differ from the stereotype, but for those who have private/cultural matching beliefs (i.e. they privately support the content of the stereotype), jokes like (34) might pose no incongruity at all.

Second, the jokes were analyzed and ascribed to a Case of the taxonomy. Initially, the source of incongruity (frame-based or discourse-centered) was spotted; secondly it was checked where this incongruity-generating element was located (setup or punchline); and then the analysis focused on the kind of resolution needed to reconcile the incongruous parts of the joke (discourse-, implication- or frame-based). The procedure to ascribe jokes to a specific Case of the taxonomy was performed mainly by tracking the key to the joke's eventual humorous effects, and by locating which inferential steps are predicted and manipulated by the speaker for the sake of obtaining these effects. However, this "inferential tracking" is performed in a neutral context (an analyst dissecting the jokes). As one reviewer of the manuscript correctly pointed out, jokes are told in a specific context and at a specific moment and directed at a specific audience. On paper, the predicted inferential steps leading to humor should be carried out similarly across different audiences, but possible interpretive variations may occur, for example due to the hearer's background knowledge, or the context within which the joke is told.

Third, a sub-analysis was carried out specifically for jokes containing discourse-centered incongruities (Cases 7 to 12), so as to determine the inferential strategy on which the incongruities are based: identification of logical form, retrieval of unarticulated constituents, reference assignment, disambiguation, and concept adjustment (see Section 5.2 below). This analysis proved to be rather difficult. Indeed, sometimes it is a challenge to work out the exact sub-strategy on which the incongruity relies and which leads to the desired effects. In Author (2016: 61), the following example is provided:

(35) A doctor began his examination of an elderly man by asking him what brought him to hospital. The old man looked surprised and said "Well, of course it was an ambulance!" 
The incongruity in this apparently simple joke seems to arise either from two senses of bring (disambiguation) or from two (ad hoc) concepts of the coded verb bring. My opinion is that it involves two (ad hoc) concepts of the typical meaning 'A causes B to go to $X$ ' conceptually adjusted to fit the two scenarios, the likely one and the unlikely (but eventually correct) one. But Deirdre Wilson (pers. comm.) points out that there are multiple candidate inferential strategies in this joke, and the range of options include:

(1) the possibility that bring is polysemous, with a range of related senses (e.g. carry to a certain place, cause to be in a certain place), which are first disambiguated and then (as always) further broadened or narrowed in context; (2) that bring has a single, concrete sense which yields a wide range of different ad hoc concepts via broadening or narrowing; and (3) that bring has a single, general sense (impel towards a certain place, where the source of the impulsion can be physical or mental) which can again be narrowed to yield different more specific ad hoc concepts in different contexts.

\section{Results and discussion}

The analysis of the corpus yielded the ascription of jokes per Case that is provided in Table 2. The ascription by topic is provided in Table 3 .

\begin{tabular}{||l|l|l|l||}
\hline Case & Type & Num. & $\%$ \\
\hline 01 & frame-based incongruity / in setup / discourse-centered resolution & 0 & 0 \\
\hline 02 & frame-based incongruity / in punchline / discourse-centered resolution & 0 & 0 \\
\hline 03 & frame-based incongruity / in setup / frame-based resolution & 49 & 9,80 \\
\hline 04 & frame-based incongruity / in punchline / frame-based resolution & 140 & 28,00 \\
\hline 05 & frame-based incongruity / in setup / implication-based resolution & 10 & 2,00 \\
\hline 06 & frame-based incongruity / in punchline / implication-based resolution & 130 & 26,00 \\
\hline 07 & discourse-centered incongruity / in setup / discourse-centered resolution & 68 & 13,60 \\
\hline 08 & $\begin{array}{l}\text { discourse-centered incongruity / in punchline / discourse-centered } \\
\text { resolution }\end{array}$ & 66 & 13,20 \\
\hline 09 & discourse-centered incongruity / in setup / frame-based resolution & 5 & 1,00 \\
\hline 10 & discourse-centered incongruity / in punchline / frame-based resolution & 3 & 0,60 \\
\hline
\end{tabular}




\begin{tabular}{||l|l|l|l||}
\hline 11 & discourse-centered incongruity / in setup / implication-based resolution & 14 & 2,80 \\
\hline 12 & $\begin{array}{l}\text { discourse-centered incongruity / in punchline / implication-based } \\
\text { resolution }\end{array}$ & 5 & 1,00 \\
\hline OT & jokes with problematic Case ascription & 10 & 2,00 \\
\hline
\end{tabular}

Table 2. Frequency in corpus of the taxonomy of IR Cases.

\begin{tabular}{|c|c|c|c|c|c|c|c|c|c|c|c|c|}
\hline 03 & 04 & 05 & 06 & 07 & 08 & 09 & 10 & 11 & 12 & OT & Total & $\%$ \\
\hline \multicolumn{13}{|c|}{ Sex } \\
\hline 9 & 31 & & 20 & 11 & 15 & 3 & 1 & 2 & & 6 & 98 & 19,6 \\
\hline \multicolumn{13}{|c|}{ Marriage } \\
\hline 8 & 33 & 2 & 13 & 15 & 10 & & & 5 & & 2 & 88 & 17,6 \\
\hline \multicolumn{13}{|c|}{ Doctor } \\
\hline 3 & 21 & 1 & 13 & 20 & 8 & 2 & & 3 & 2 & & 73 & 14,6 \\
\hline \multicolumn{13}{|c|}{ Lawyer } \\
\hline 1 & 4 & 3 & 50 & 3 & & & & 1 & 2 & & 64 & 12,8 \\
\hline \multicolumn{13}{|c|}{ Bar } \\
\hline 18 & 12 & 3 & 2 & 6 & 11 & & & 1 & 1 & 1 & 55 & 11,0 \\
\hline \multicolumn{13}{|c|}{ Jobs } \\
\hline 2 & 14 & & 5 & 1 & 7 & & 1 & & & & 30 & 6,0 \\
\hline \multicolumn{13}{|c|}{ Man \& Woman } \\
\hline 3 & 5 & & 6 & 2 & 3 & & & & & 1 & 20 & 4,0 \\
\hline \multicolumn{13}{|c|}{ Blonde } \\
\hline 2 & 1 & 1 & 8 & 2 & 3 & & & 2 & & & 19 & 3,8 \\
\hline \multicolumn{13}{|c|}{ Sport } \\
\hline & 6 & & 4 & 1 & 3 & & & & & & 14 & 2,8 \\
\hline
\end{tabular}




\begin{tabular}{|c|c|c|c|c|c|c|c|c|c|}
\hline \multicolumn{10}{|c|}{ Family } \\
\hline 5 & & 4 & 2 & & & 1 & & 12 & 2,4 \\
\hline \multicolumn{10}{|c|}{ Religion } \\
\hline 1 & 2 & & & 3 & & & & 6 & 1,2 \\
\hline \multicolumn{10}{|c|}{ Travel } \\
\hline 1 & & & 3 & 1 & 1 & & & 6 & 1,2 \\
\hline \multicolumn{10}{|c|}{ Other } \\
\hline 1 & 6 & & 2 & & 5 & & 1 & 15 & 3,0 \\
\hline
\end{tabular}

Table 3. Frequency in corpus of the taxonomy of IR Cases arranged by topic.

The ascription of inferential sub-strategies per Case is listed in Table 4. The difference in total amount for Cases 7-8 compared to results in Table 2 is due to the fact that some of the jokes labeled as "problematic Case ascription" (see below) do contain the type of incongruity defining these two Cases, even if not fully. For example, some of the problematic jokes exhibited more than one discourse-centered sub-strategy involved in the incongruity (see Section 5.3 below), although both fitted a specific Case.

\begin{tabular}{|c|c|c|c|c|}
\hline Case & Type & & Num. & $\%$ \\
\hline \multirow[t]{5}{*}{07} & Logical form & 5 & & \\
\hline & Unarticulated constituents & 8 & & \\
\hline & Reference assignment & 14 & & \\
\hline & Disambiguation & 22 & & \\
\hline & Concept adjustment & 21 & 70 & 40,93 \\
\hline \multirow[t]{5}{*}{08} & Logical form & 5 & & \\
\hline & Unarticulated constituents & 2 & & \\
\hline & Reference assignment & 6 & & \\
\hline & Disambiguation & 31 & & \\
\hline & Concept adjustment & 30 & 74 & 43,27 \\
\hline
\end{tabular}




\begin{tabular}{||l|lr|r|l||}
\hline 09 & Unarticulated constituents & 1 & & \\
& Reference assignment & 2 & & \\
& Disambiguation & 1 & & \\
& Concept adjustment & 1 & 5 & 2,93 \\
\hline 10 & Reference assignment & 2 & & \\
& Concept adjustment & 1 & 3 & 1,75 \\
\hline 11 & Unarticulated constituents & 1 & & \\
& Reference assignment & 1 & & \\
& Disambiguation & 6 & & \\
& Concept adjustment & 6 & 14 & 8,19 \\
\hline 12 & Disambiguation & 1 & & \\
& Concept adjustment & 4 & 5 & 2,93 \\
\hline \hline
\end{tabular}

Table 4. Inferential sub-strategies performed for jokes fitting Cases 7-12.

The analysis of the corpus of jokes yields some preliminary conclusions. Designers of jokes seem to prefer to base their humorous effects on the construction of a make-sense frame, which is invalidated and a resolution has to be found for the incongruity generated in terms of a new frame or the derivation of implicatures. 329 jokes out of a corpus of $490(67,14 \%, 10$ jokes with problematic ascription excluded) fit this humorous strategy. A possible explanation is that make-sense frames are typically constructed "on the fly", almost unconsciously, and hence it is more effective to surprise the hearer by reminding him/her that this unconsciously constructed scenario is not valid and has to be replaced with a different one or entails the derivation of a number of implications. By contrast, discourse-centered incongruities (161 jokes, 32,86\%) demand from the hearer a more conscious interpretive procedure and the resolution of the incongruity usually demands the location and reinterpretation of very specific items within the joke, for example to seek for a different referent for an indexical, or engage in a specific adjustment of the concept coded by a word, or selecting a different sense of an ambiguous word.

Besides, designers prefer what can be labeled forward incongruities (344 out of 490, 70,2\%), compared to backward incongruities (146 out of $490,29,8 \%$ ). The latter refers to joke configurations in which the hearer, upon detecting an incongruity at the end of the joke (punchline), is forced to return to an already processed part of the joke and engage in some inferential backtracking. This strategy is intended to build up a different scenario for the setup of the joke (make-sense frame) or to re-interpret some portion of text belonging to the setup in the light of the interpretation obtained for the punchline of the joke (a different referent, an alternative sense of a word, a new adjustment for a concept, etc.). By contrast, forward incongruities involve inferential procedures that demand from the 
hearer a construction of a new frame that resolves the incongruity for the whole joke, or the derivation of a number of implicatures (stronger or weaker). The construction of these frames and the derivation of these implicatures add to, as it were, rather than alter, the processing of the joke. This addition is, to a certain extent, the hearer's responsibility and therefore an offset of satisfaction is added to the joy of solving the incongruity. The hearer has, after all, found the solution by himself/herself, so a degree of personalization is added to the relevance of the joke in terms of humorous effects.

Furthermore, and beyond the utterly strong implicatures that are clearly meant by the speaker as part of the generation of humorous effects, the hearer may come up with a number of weak implicatures, not really intended by the speaker, but which make up part of the eventual derivation of humorous effects. These weak implicatures add to the feeling of personal incongruity-solving. Jodłowiec (2015: 117-119) addresses this personal derivation of hearer-supported implicatures in terms of a cognitive overload of assumptions tied to humorous effects and laughter. She proposes this example:

(36) Harry invites his old friend John home for dinner one evening. At the dinner table, Harry talks to his wife using endearing terms, such as Honey, My Love, Darling, Sweetheart, Pumpkin, etc. The couple have been married for almost 30 years and John's truly impressed. When Harry's wife is out of the room, John leans over and says, "I think it's wonderful that, after all these years, you still call your wife those loving pet names. What is the secret to this long-lasting marital happiness?" Harry replies: "To tell you the truth, I forgot this woman's name a couple of years ago and it's a bit awkward to ask now".

Jodłowiec (ibid.: 118) correctly stresses that, upon inferring (36), many assumptions are likely to be derived by the hearer, some clearly related to husbands' attitudes to their wives, for instance those listed in (37a-b), communication problems within marriage (e.g. 37c-d), and the unfeasibility of longlasting happiness (e.g. 37e-f), among others:

(37) a. Husbands often exhibit a careless attitude to vital detail of everyday life.

b. Husbands often take it for granted that their wives are part of their lives.

c. Husbands and wives often find it difficult to talk to each other about important issues.

d. Married couples do not spend much time sharing what they really think.

e. As the marriage lasts longer, true affection in the marriage decreases.

f. After several years, married couples forget what affection is.

There is no guarantee that few (if any) of these assumptions will end up being represented by the hearer, so they can just be pictured as creating a "cognitive overload" in which a vast number of assumptions become suddenly manifest (or more manifest) to the hearer, with none or perhaps very 
few of them being actually represented. As Jodłowiec (ibid.: 119) concludes, "even though none of them can strictly speaking be identified as part of the intended interpretation, the whole effect involving a vast array of weakly communicated assumptions, whatever they might be for different recipients, is assumed to be intended as part of the joke interpretation, so these assumptions have the status of weak implicatures".

\subsection{Make-sense frame-based incongruities}

As has already been mentioned, forward frame-based incongruities are more frequent, typically placed at the end of the joke (punchline). These either require the construction of a new frame for the whole joke (Case 4, 42,55\% of frame-based jokes; $28,60 \%$ of total of corpus), or demand from the hearer the derivation of a number of strong implicatures, some of them clearly backed up by the speaker and others maybe recovered by the hearer's sole responsibility, as is the case with weak implicatures (Case $6,39,51 \%$ of frame-based jokes; $26,53 \%$ of total of corpus). Consider these jokes:

(38) Bill sat alone in the hospital room at his dying wife's beside. "Bill darling", she breathed. "I've got a confession to make before I go... I... I'm the one who took the $\$ 10,000$ from your safe in the house... I spent it on a fling with your best friend Jimmy. For years I've been going to bed with Jimmy, as well as with several of the neighbors". "That's all right dearest; I knew that already", said Bill, "that's why I poisoned you".

(39) It was laying limp in my hand. It was very long, kind of thin. I slid it between my fingers until I got to the end of it. I was turning it on. It became firm in my hands, and the end was wet. Then it got very hard and began gushing out of the tip. Then I took the garden hose and watered the bushes.

(40) A man asked his doctor if he thought he'd live to be a hundred. The doctor asked the man, "Do you smoke or drink?" "No", he replied, "I've never done either". "Do you gamble, drive fast cars, and fool around with women?" inquired the doctor. "No, l've never done any of those things either". "Well then", said the doctor, "what do you want to live to be a hundred for?"

In (38), the frame "grieving man with dying wife" is easy to construct, accessible and relevant for most of the text of the joke, until the punchline forces the hearer to replace this frame with a different and unexpected one. The key to the humorous effect lies in the drastic change provoked in the frame constructed so far and their replacement with a new surprising one for the whole joke. (39) is understood as fitting the description of male masturbation, but at the end the hearer realizes that the whole joke fits another scenario: that of a man watering the garden. Finally, in (40) the hearer constructs a frame for the joke in which healthy habits are positive, but the end of the joke alters this frame and forces a change of scenario. In all of these cases, the hearer processes the whole joke and 
then, after an incongruity is found in the punchline, builds up another frame for the whole joke, thus fitting the quality of forward incongruity outlined above.

Similarly, the jokes in Case 6 also fit the quality of forward incongruity, since they mainly base the generation of humorous effects on a number of implicatures derived from the text of the joke after it has been processed and an incongruity is found in the punchline. Again, the hearer interprets the joke and then derives a number of strong/weak implicatures that eventually lead to a relevant (and humorous) interpretation of the text of the joke. Consider these jokes:

(41) A young man, hired by a supermarket, reported for his first day of work. The manager greeted him with a warm handshake and a smile, gave him a broom and said, "Your first job will be to sweep out the store". "But I'm a college graduate", the young man replied indignantly. "Oh, I'm sorry. I didn't know that", said the manager. "Here, give me the broom, I'll show you how".

(42) I've never been much on fashion, but got quite a few compliments on a new sports jacket I wore to work one day. My secretary asked me where I got it and I told her that it was a surprise from my wife. I went home early yesterday, and there it was, on the back of a kitchen chair.

Joke (41) bases the humorous effects on the derivation of a number of implicatures concerning the value of university training and degrees, after the joke has been interpreted and an incongruity is found in the punchline. A similar case is (42), whose relevance can only be obtained if the hearer derives implicated premises and conclusions about why a jacket ends up on the back of the chair, implicatures probably related to an affair of the wife's.

Regarding joke topic (Table 3 above), most of the jokes fit these Cases 4 and 6 , which are especially suited to deal with social stereotypes (marriage, sex roles...). An interesting case is "lawyer jokes": 50 out of the 64 lawyer jokes $(78,12 \%)$ fit Case 6 . A possible explanation is that the joke designer relies on a mutuality of information on the negative qualities of lawyers, but prefers the hearer to take the responsibility in deriving these qualities via implicatures, as in (43) and (44) below, rather than stating them bluntly within the joke:

(43) Two lawyers walking through the woods spotted a vicious-looking bear. The first lawyer immediately opened his briefcase, pulled out a pair of sneakers and started putting them on. The second lawyer looked at him and said, "Are you crazy? You'll never be able to outrun that bear!". "I don't have to", the first lawyer replied. "I only have to outrun you".

(44) An airliner was having engine trouble, and the pilot instructed the cabin crew to have the passengers take their seats and get prepared for an emergency landing. A few minutes later, the pilot asked the flight attendants if everyone was buckled in and ready. "All set back here, Captain", came the reply, "except the lawyers are still going around passing out business cards". 


\subsection{Discourse-centered incongruities}

In the case of discourse-centered incongruities, the most frequent Cases fit what can be labeled symmetrical incongruity-resolution, that is, cases in which both the incongruity and the resolution are based on the same type of inferential sub-strategy. This is a common feature in most Cases of the taxonomy (including those relying on frame-based incongruities), but it is particularly frequent in discourse-centered incongruities, since the same sub-strategy used as a source of incongruity is typically the same sub-strategy that is applied to finding a resolution to the incongruity encountered. This symmetry may also aid addressees in determining the expected form of resolution, thus aiding in saving mental effort when obtaining the desired humorous effects.

The Cases in which this pattern is more frequent are Case 7, in which the source of incongruity is placed in the setup of the joke (68 jokes, $42,23 \%$ of all discourse-centered jokes), and Case 8 , with the source of incongruity placed in the punchline (66 jokes, $41 \%$ of all discourse-centered jokes). The typical strategy here is to play with the accessibility and likelihood of the interpretations selected for a specific stretch of the joke text: a referent for an indexical that is very likely and then invalidated, a sense of an ambiguous word which is easy to access and then the hearer realizes that this relevant sense selected is not the eventually correct one, a slightly different ad hoc concept to the one adjusted initially, a different arrangement of the semantic representation or logical form of the utterance, etc.

\begin{tabular}{|c|c|c|c|c|c|c|c|}
\hline 07 & 08 & 09 & 10 & 11 & 12 & Total & $\%$ \\
\hline \multicolumn{8}{|c|}{ Logical form } \\
\hline 5 & 5 & & & & & 10 & 5,85 \\
\hline \multicolumn{8}{|c|}{ Unarticulated constituents } \\
\hline 8 & 2 & 1 & & 1 & & 12 & 7,01 \\
\hline \multicolumn{8}{|c|}{ Reference assignment } \\
\hline 14 & 6 & 2 & 2 & 1 & & 25 & 14,61 \\
\hline \multicolumn{8}{|c|}{ Disambiguation } \\
\hline 22 & 31 & 1 & & 6 & 1 & 61 & 35,68 \\
\hline \multicolumn{8}{|c|}{ Concept adjustment } \\
\hline 21 & 30 & 1 & 1 & 6 & 4 & 63 & 36,85 \\
\hline
\end{tabular}


Table 5. Global results for inferential sub-strategies performed in jokes fitting Cases 7-12.

The discourse-centered sub-strategies performed in the jokes are listed in Table 5. The most frequent sub-strategy is concept adjustment, in jokes such as (45-47) below, which entail a new readjustment of the encoded concepts fool, shark and hurt in the light of the interpretation for the last part of the jokes:

(45) Following a bitter divorce a husband saw his wife at a party and sneered, "You know, I was a fool when I married you". The wife simply sighed and replied, "Yes, dear, I know, but I was in love and didn't really notice".

(46) A doctor was vacationing at the seashore with his family. Suddenly, he spotted a fin sticking up in the water and fainted. "Darling, it was just a shark", assured his wife when he came to. "You've got to stop imagining that there are lawyers everywhere".

(47) Patient (to cosmetic surgeon): Will it hurt me, doctor?

Surgeon: Only when you get my bill, Mrs Brown.

However, and unlike initial expectations, the humorous strategy of playing with literal and figurative (metaphoric or idiomatic) interpretations of whole phrases and utterances was not frequent in the corpus. Only jokes (48) and (49) neatly matched this strategy. In these jokes, the speaker plays with the idiomatic versus literal interpretations of drop dead and scratch one's balls, respectively. Besides, there is an expectation that both senses should remain vivid in the hearer's mind, rather than one replacing the other:

(48) Tim had died of a heart attack. All his friends didn't know how to break the news to his wife, finally Johnny said: 'I can be diplomatic about it and break the news gently!'. Johnny rang the bell at Tim's house, and when his wife answered the door, he calmly said to her: 'Tim just gambled with us and lost 1,000 dollars!' When Tim's wife heard this she said: 'Tell him to just drop dead!' Johnny answered: 'That's exactly what he did!'.

(49) A man was being interviewed for a job. "Were you in the service?" ask the interviewer. "Yes, I was a marine", responded the applicant. "Did you see any active duty?" "I was in Vietnam for 2 years and I have a partial disability". "May I ask what happened?" "Well, I had a grenade go off between my legs and I lost both testicles". "You're hired. You can start Monday at 10 am". "When does everyone else start? I don't want any preferential treatment because of my disability". "Everyone else starts at 7 am but I might as well be honest with you. Nothing gets done between 7 and 10 . We just sit around scratching our balls trying to decide what to do first".

The second most frequent sub-strategy is disambiguation. This is a particularly effective tool for the 
generation of humorous effects, since hearers are not really aware that they are performing the inferential task of disambiguation. ${ }^{3}$ Unlike concept adjustment, in which there is some resemblance between the coded concept and the eventually inferred ad hoc concept, disambiguation deals with utterly different senses, one of which is never entertained due to its irrelevance in the context within which it appears. Indeed, normally, the information already processed or the context in which it is processed makes one of the senses much more likely and relevant, the hearer not noticing that another sense of the word is possible. An often cited example is (50) below, in which the interpretation of the preceding text makes one single interpretation of bat relevant in both utterances:

(50) Your team is disqualified from the baseball game. Peter's bat is too grey.

We've chosen John's mouse for the experiment. Peter's bat is too grey.

In humor, this unawareness of potentially ambiguous words is particularly useful, since the speaker can surprise the hearer with senses of a word that the hearer could not possibly have entertained, thus creating a higher level of incongruity and an awareness (now conscious) of the variety of senses through its resolution. Examples include responsible in (51) and come in (52):

(51) Employer to applicant: "In this job we need someone who is responsible". Applicant: "I'm the one you want. On my last job, every time anything went wrong, they said I was responsible".

(52) "Do you have any batteries?" a woman asks the hardware store clerk. "Yes, madam". The clerk gestures with his finger. "Can you come this way?" "If I could come this way", the woman says, "I wouldn't need the batteries".

A particularly frequent schema in this sub-strategy is to force the hearer into entertaining both senses of an ambiguous word simultaneously, rather than one sense being replaced with the other, as has already been suggested. Although this is counter-productive for human cognition, always eager to rule out incongruities, the presumption and mutual manifestness of the intended humorous effects makes the hearer be willing to engage in this unresolved ambiguity and entertain both senses with amusement. This is what Forabosco (1992: 59) calls incongruity turning into "congruent incongruity", in the sense that two incompatible meanings or situations evoked by a humorous stimulus are still available after the resolution process, so that they are perceived as both incongruent and congruent at the same time (see Canestrani and Bianchi, 2013). Examples include pointless in (53) and period in (54):

3. This would be especially the case of jokes which are craftily embedded in the conversation and catch the hearer by surprise. On some occasions, though, the fact that the hearer is alerted of a forthcoming joke (e.g. Have you heard the one...?) may raise the level of vigilance that the hearer devotes to the processing of the text of the joke, and hence be more alert to alternative meanings of ambiguous words. Thanks to a reviewer of the manuscript for pointing this out to me. 
(53) Did you hear the joke about the football game with the 0-0 score?

Never mind it's pointless.

(54) Have you heard about the new line of Tampax with bells and tinsel?

It's for the Christmas period.

The third most frequent sub-strategy is reference assignment, typically associated with indexicals. As happens with disambiguation, the speaker also plays with a range of possible referents in a context, which are graded in terms of relevance, one of them being very likely (but eventually incorrect), and one of them not being taken into consideration (but eventually turning out correct). Examples include the referent for it in (55) and for three in (56):

(55) A doctor and a nurse were called to the scene of an accident.

Doctor: We need to get these people to a hospital now!

Nurse: What is it?

Doctor: It's a big building with a lot of doctors, but that's not important now!

(56) The newlywed wife said to her husband when he returned from work, "I have great news for you. Pretty soon, we're going to be three in this house instead of two". Her husband ran to her with a smile on his face and delight in his eyes. He was glowing of happiness and kissing his wife when she said, "I'm glad that you feel this way since tomorrow morning, my mother moves in with us".

Finally, two rather infrequent sub-strategies in the corpus include the inferential retrieval of unarticulated constituents, typical of sub-sentential utterances, and the variety of possible arrangements for sentence constituents yielding alternative logical forms. An example of the latter would be the dual arrangements (58a-b) for joke (57):

(57) A man is driving down a country road when he spots a farmer standing in the middle of a huge field of grass. He pulls the car over to the side of the road and notices that the farmer is just standing there, doing nothing, looking at nothing. The man gets out of the car, walks all the way out to the farmer and asks him, "Ah excuse me mister, but what are you doing?" The farmer replies, "I'm trying to win a Nobel Prize". "How?" asks the man, puzzled. "Well I heard they give the Nobel Prize to people who are out standing in their field".

(58) a. people who are [outstanding] [in their field].

b. people who are [out] [standing] [in their field].

5.3. Problematic Case ascription 
Not all the jokes in the corpus fitted neatly one Case in the proposed IR taxonomy. Sometimes difficulties arose due to specific joke configurations, which applies to 10 of the samples. Firstly, the dividing line between incongruities based on make-sense frame construction and those centered upon discourse comprehension is often blurred. In general, as was suggested above, frames aid in discourse-centered incongruities, but in this case, the main source of incongruity is still ascribable to a specific stretch of discourse demanding a specific inferential sub-strategy. Consider the joke in (59):

(59) Customer: l'd like to buy a novel, please.

Bookshop assistant: Certainly, madam. Do you have the title or name of the author?

Customer: Not really. I was hoping you could suggest something suitable.

Bookshop assistant: No problem. Do you like light or heavy reading?

Customer: It doesn't matter. I've left the car just outside the shop.

In this example, the speaker knows that the hearer will activate the "buying a book" make-sense frame at the beginning of the joke, which connotes the processing of subsequent stretches of text. In this scenario, the speaker knows that heavy will inevitably be understood as "difficult or demanding" instead of "weighing a lot", since the just-constructed make-sense frame favors this interpretation, suitable in this context and demanding little mental effort (Author, 2016: 122). This joke fits discoursecentered incongruity aided by make-sense frame construction. On other occasions, though, jokes exhibit a more complicated pattern, as in (60):

(60) A recent survey done by marriage experts shows that the most common form of marriage proposal these days consists of the words: "You're what???".

This joke entails the combination of frame construction and discourse comprehension, but not fitting the pattern of the former aiding in the extent of the incongruity focused on the latter. Instead, it seems to work in a different direction: to search for a suitable referent for what (as a discourse-centered resolution) aids in changing the make-sense frame from "desired marriage" into "forced marriage", also a form of resolution.

Secondly, sometimes more than one single frame is constructed and invalidated, which makes Case ascription difficult. An example is joke (61), in which an initial frame (sex with prostitute) is invalidated in the middle of the joke (upon reaching "What kind of woman do you think...?") and then the frame is invalidated again and the hearer has to return to the initial frame:

(61) "Would you sleep with me for ten thousand dollars?", asked John. "Yes, I will", Paula replied. "Would you do it for one thousand?", he asked. "Well maybe, or maybe l'd do something else for 
you", she answered with a wink. "How about oral sex for \$20?", responded John. "Hey! What kind of woman do you think I am?", Paula snapped, indignantly. "That's already been established, Paula. Now we're just haggling over the price!".

Thirdly, sometimes the source of incongruity is not either located in the setup or in the punchline, but all over the joke. For example, joke (62) is based upon finding an alternative referent for the pronoun this, but this assignment is performed all over the joke, without a clear setup-punchline distinction:

(62) Q: How do you tell if you're making love to a nurse, a schoolteacher, or an airline stewardess?

A: A nurse says: "This won't hurt a bit". A schoolteacher says, "We're going to have to do this over and over again until we get it right". An airline stewardess says, "Just hold this over your mouth and nose, and breathe normally".

Fourthly, sometimes more than one discourse-centered incongruity and/or resolution sub-strategy is needed for the joke to generate the expected humorous effects, thus not neatly fitting the pattern of one sub-strategy per Case. Consider these jokes:

(63) Q. What's long, hard and full of semen?

A. A submarine.

(64) A couple married after graduating, are driving from Dallas down to a motel in Austin for their honeymoon. Along the way, he reaches over and puts his hand on her knee. She smiles, blushes and says, "Oh, we're married now, you can go farther than that!". So he drove on to Laredo.

In (63), the source of incongruity relies on the inference of three words located in the setup of the joke. However, several inferential sub-strategies are involved in obtaining humorous effects: concept adjustment for long and hard, and disambiguation for semen/seamen, which are near homophones. Similarly, joke (64) entails both concept adjustment for the scope covered by the encoded concept farther, and also reference assignment for that, one referent being very likely and relevant (the woman's knee) and one very unlikely but eventually correct (a place along the way).

Fifthly, on some occasions it is utterly difficult to draw a clear dividing line between incongruities whose resolution only requires the construction of a new frame or a new discourse-centered interpretation, and those whose main resolution lies in the derivation of a number of implicatures, some of which will be clearly supported by the speaker (strong implicatures) and some drawn by the hearer's sole responsibility but nevertheless triggered by the joke content (weak implicatures). On the one hand, some jokes base their effectiveness on the combination of resolutions based on a specific sub-strategy and the need to draw implicatures from the interpretation obtained, rather than only on 
that sub-strategy or on the implications. Consider this joke:

(65) On her way home from a long trip, a blonde drove past a sign that said "CLEAN RESTROOMS 8 MILES". By the time she drove eight miles, she had cleaned 43 restrooms.

Jokes which play with social stereotypes (the wicked lawyer, sex roles, etc.) typically rely on a mutual manifestness of information about these stereotypes, and their reinforcement is usually achieved not in the joke, but through the implicatures drawn from it, after the joke itself has been processed for relevance. So-called "blonde jokes" such as (65) above are a typical example. The joke relies on unarticulated constituents in the sign, which allows for different possible logical forms and interpretations, but the main point of the joke is to reinforce the "blonde is dumb" stereotype via implicated premises and conclusions (implicatures).

And on the other hand, as was illustrated above with the example by Jodłowiec (2015: 117-119), there is no guarantee that the hearer will stop processing the joke after constructing an alternative make-sense frame or engaging in a specific discourse-centered sub-strategy (as intended by the speaker). Indeed, some hearers may take the text of the joke as the starting point for the derivation of a number of "personal" weak implicatures, most of them beyond the speaker's expectations and predictions of relevance.

Finally, some problems for ascription may turn up when dealing with some types of jokes, for example nonsense jokes, for which it is difficult to engage in make-sense construction. Besides, as was commented upon above, problems arise with jokes containing stereotype-consistent information, which may be regarded as congruous (no incongruity found) if this stereotypical information matches the hearer's own personal beliefs concerning the stereotype depicted. In this case, the joke itself would not even exhibit an IR pattern.

\section{Concluding remarks}

In this paper, a corpus of five hundred jokes has been analyzed and the extent to which they fit any of twelve Cases of incongruity-resolution patterns has been studied. Most of them fitted one of these Cases, with a few problematic cases, while no sample jokes were found for two of the Cases in the taxonomy.

Prospects of future research include moving beyond the Anglo-Saxon cultural background of these jokes (the website jokes2go.net) and into jokes from a different culture and check whether the patterns exhibited by the jokes produced within that culture (for example jokes in peninsular Spanish arising from the Spanish culture) differ or not from the ones analyzed in this paper, both in terms of typical IR cases, sub-strategies involved for discourse-centered jokes, and topics of the jokes in the corpus selected. Similarly, the fact that certain cultures are more prone to specific types of IR (for 
example, jokes involving punning configurations are typical in the Anglo-Saxon culture) may play a part in how much mental effort is devoted to both finding incongruities and working on possible resolutions.

Overall, the taxonomy highlights the way inferential strategies are planned by humorists and, at the same time, neatly fits the general relevance-theoretic model of inference. In future research, it will be profitable to assess the extent to which other models of humorous communication fit into the foundations of this taxonomy, which also has applications in broader areas of humor research such as longer monologues (e.g. stand-up comedy), even if the exact extent and depth of incongruityresolution has to be adjusted to the new format, together with the aforementioned challenge of stereotype-consistent texts, which may pose no incongruity to some part of the audience.

\section{References}

Attardo, S. 1994. Linguistic Theories of Humor. Mouton de Gruyter, Berlin.

Beattie, J . 1776. Essay on laughter and ludicrous composition. In: Essays. William Creech, Edinburgh.

Canestrari, C., Bianchi, I., 2013. From perception of contraries to humorous incongruities. In: Dynel, M. (Ed.), Developments in

Linguistic Humour Theory. John Benjamins, Amsterdam and Philadelphia, pp. 3-24.

Carston, R., 2002. Thoughts and Utterances. Blackwell, Oxford.

Carston, R., 2009. Explicit/implicit distinction. In: Cummings, L. (Ed.), The Pragmatics Encyclopedia. Routledge, London.

Curcó, C., 1997. The Pragmatics of Humorous Interpretations: A Relevance-Theoretic Account. Unpublished PhD. Dissertation. University College London, London.

Curcó, C., 1998. Indirect echoes and verbal humour: In: Rouchota, V., Jucker, A. (Eds.), Current Issues in Relevance Theory. John Benjamins, Amsterdam and Philadelphia.

Dynel, M., 2012. What RT cannot do, IR can: On the incremental interpretation of jokes in (non)relevance-theoretic terms. In: Wałaszewska, E., Piskorska, A. (Eds.), Relevance Theory: More than Understanding. Cambridge Scholars Publishing, Newcastle upon Tyne, pp. 147-166.

Fearman, R.J., 2014. Punchline predictability, comprehension speed, and joke funniness: Investigating incongruity theories of humour. University of Western Ontario (Canada), Undergraduate Honors Thesis, Paper 5.

Forabosco, G., 1992. Cognitive aspects of the humor process: The concept of incongruity: Humor 5(1/2), 45-68.

Freud, S. 1916. Wit and its Relation to the Unconscious. Moffat Ward, New York.

Halkias, G., Kokkinaki, F., 2016. Schema strength, processing opportunity, and the rewarding nature of incongruity resolution in advertising. International Journal of Advertising.

Hirt, M., Genshaft, J., 1982. The effects of incongruity and complexity on the perception of humor. Personality and Individual Differences 3(4), 453-455.

Hull, R., Tosun, S., Vaid, J., 2016. What's so funny? Modelling incongruity in humour production. Cognition and Emotion.

Jodłowiec, M., 2008. What's in the punchline? In: Wałaszewska, E., Kisielewska-Krysiuk, M., Korzeniowska, A., Grzegorzewska, M. (Eds.), Relevant Worlds: Current Perspectives on Language, Translation and Relevance Theory. Cambridge Scholars Publishing, Newcastle-upon-Tyne, pp. 67-86.

Jodłowiec, M., 2015. The Challenges of Explicit and Implicit Communication. A Relevance-Theoretic Approach. Peter Lang, Berlin.

Kant, I. 1790. Kritik der Urteilskraft. Lagarde, Berlin.

Keith-Spiegel, P. 1972. Early conceptions of humor: Varieties and issues. In: Goldstein, J.H., McGhee, P.E. (Eds.), The Psychology of Humor. Theoretical Perspectives and Empirical Issues. Academic Press, New York, pp. 4-39.

Martin, R.A., 2006. The Psychology of Humor: An Integrative Approach. Academic Press, London. 
Nerhardt, G., 1976. Incongruity and funniness: Toward a new descriptive model. In: Chapman, A.J., Foot, H. (Eds.), Humour and Laughter: Theory, Research and Applications. John Wiley \& Sons, London, pp. 55-62.

Plester, B., 2016. The Complexity of Workplace Humour. Laughter, Jokers and the Dark Side of Humour. Springer, Berlin.

Ritchie, G., 2004. The Linguistic Analysis of jokes. Routledge, Abingdon.

Ritchie, G. 2006. Reinterpretation and viewpoints. Humor 9(3), 251-270.

Schopenhauer, A. 1819. Die Welt als Wille und Vorstellung. Brockhaus, Leipzig.

Sperber, D., Wilson, D., 1995. Relevance. Communication and Cognition (2nd edition). Blackwell, Oxford.

Suls, J.M., 1972. A two-stage model for the appreciation of jokes and cartoons: An information-processing analysis. In: Goldstein, J.H., McGhee, P.E. (Eds.), The Psychology of Humor: Theoretical Perspectives and Empirical Issues. Academic Press, New York, pp. 81-100.

Suls, J.M., 1977. Cognitive and disparagement theories of humour: A theoretical and empirical synthesis. In: Chapman, A.J., Foot, H.C. (Eds.), It's a Funny Thing, Humour. Pergamon Press, Oxford, pp. 41-45.

Suls, J.M., 1983. Cognitive processes in humor appreciation. In: McGhee, P.E., Goldstein, J.H. (Eds.), Handbook of Humor Research, Vol. 1: Basic Issues. Springer-Verlag, New York, pp. 39-57.

Thielemann, N. 2015. From discourse structure to cognition (and back) -Humorous blends in conversation. Wiener Slawistischer Almanach 75, 189-228.

Yoon, H.J., 2013. Understanding schema incongruity as a process in advertising: Review and future recommendations. Journal of Marketing Communications 19(5), 360-376. 